\title{
Pyrolysis Modelling of PVC Cable Materials
}

\author{
ANNA MATALA, and SIMO HOSTIKKA \\ VTT Technical Research Centre of Finland \\ P.O.Box 1000 \\ FI-02044 VTT, Finland
}

\begin{abstract}
One of the most commonly used materials in electrical cables is flexible PVC. In this work, the effects of the modelling decisions and parameter estimation methods on the pyrolysis modelling of two PVC cables were studied. The kinetic and thermal parameters were estimated from TGA and cone calorimeter experiments. The role of the plasticizers was shown to be important for the early HRR. The effects of the reaction path and reaction order were only minor in the TGA results but significant effects were found in the cone calorimeter results, unless a specific set of thermal parameters was estimated. The results show that the thermal parameters estimated for one kinetic model should not be used for another, unless the kinetic models only differ in fuel yields or different pairs of kinetic coefficients with same reaction order.
\end{abstract}

KEYWORDS: pyrolysis, modelling, heat release rate, reaction parameters, electrical cables.

\section{NOMENCLATURE LISTING}

$\begin{array}{llll}A & \text { frequency factor }\left(\mathrm{s}^{-1}\right) & \text { Greek } & \\ c & \text { specific heat capacity }(\mathrm{kJ} / \mathrm{kg} \cdot \mathrm{K}) & \beta & \text { heating rate }(\mathrm{K} / \mathrm{s}) \\ E & \text { activation energy }(\mathrm{kJ} / \mathrm{kmol}) & \varepsilon & \text { emissivity } \\ H_{r} & \text { heat of reaction }(\mathrm{kJ} / \mathrm{kg}) & \rho & \text { density }\left(\mathrm{kg} / \mathrm{m}^{3}\right) \\ H_{c} & \text { heat of combustion }(\mathrm{kJ} / \mathrm{kg}) & \text { subscripts } & \\ k & \text { thermal conductivity }(\mathrm{W} / \mathrm{m} \cdot \mathrm{K}) & i & \text { component } i \\ N_{m} & \text { number of material components } & j & \text { reaction } j \\ N_{r} & \text { number of reactions } & p & \text { reference } \\ N_{s} & \text { reaction order } & s & \text { solid } \\ R & \text { gas constant }(8.3145 \mathrm{~J} /(\mathrm{mol} \cdot \mathrm{K})) & & \\ T & \text { temperature }\left(\mathrm{K},{ }^{\circ} \mathrm{C}\right) & & \end{array}$

\section{INTRODUCTION}

Polyvinyl chloride (PVC) is one of the most versatile thermoplastic materials due to its processability and range of different applications. PVC is widely used in electrical cables in the form of flexible PVC. Flexible PVC is produced by adding 30-40 wt. \% additives, especially plasticizers to lower the glasstransition temperature [1]. Flexible PVC ignites more easily and burns at higher rate than rigid PVC because the plasticizers are usually combustible [2].

Electrical cables are the primary fire load in many fire engineering applications. The numerical simulation of the PVC cable fires requires the modelling of the cable pyrolysis, which is extremely challenging due to the geometrical complexity and the wide range of different PVC compositions and plasticizers. As the cable manufacturers seldom provide information about the exact chemical composition of the material, the fire modelling must be based on testing the modelling decisions against available experimental evidence. The modelling decisions are related to the degree of geometrical complexity, the number of independent material components, number of reactions and the reaction paths. The different approaches for modelling the kinetics of PVC degradation have been studied by Marcilla and Beltrán [3] who concluded that two parallel reactions are needed to describe the first stage of PVC degradation, and a single reaction for the second. The degree of model complexity should be in balance with the amount of experimental evidence and the allowable estimation and computing times. For instance, electrical cables have typically a cylindrical shape but non-symmetric inner structure with several layers of materials. How much of the layer structure is retained in the pyrolysis model, is a modelling decision. Once the model structure has been fixed, the problem becomes a parameter estimation problem, as explained in Refs. [4-8]. 
This work studies the sensitivity of the pyrolysis model to modelling decisions concerning the reaction path, reaction order and estimation method. The goal is to find the best practises of modelling complex materials such as PVC. Different modelling decisions are tested in the light of their capability to reproduce the experimentally observed behaviour in Cone calorimeter. First, models assuming a parallel reaction path are estimated for the two sample materials taking into account the softeners. An alternative reaction path is then created and the results compared to the parallel model keeping the thermal parameters fixed. The sensitivity on the kinetic parameters is studied by using two alternative estimation methods. The significance of the reaction order parameter is examined.

\section{MATERIALS AND METHODS}

\section{Materials}

The fire behaviour of two electrical cables is studied: a four conductor power cable (MCMK $4 \times 1.5 \mathrm{~mm}^{2}$ ) and a three conductor power cable (AHXCMK $10 \mathrm{kV} 3 \times 95 / 70 \mathrm{~mm}^{2}$ ), referred as Cable 1 and Cable 2, respectively. Cable 1 has a PVC sheath and insulation, and an unknown filler material. From Cable 2, only the PVC sheath is studied in this work. The cable dimensions and weights of the cable components are listed in Table 1.

Table 1. Mass fractions of the cable components. $D$ denotes cable diameter.

\begin{tabular}{|clccccc|}
\hline & Sheath & Filler & Insulation & Conductor & $\begin{array}{c}\text { Other } \\
\text { plastic }\end{array}$ \\
\hline Cable 1 & Material & PVC & - & PVC & Copper & - \\
\cline { 2 - 7 }$D=13 \mathrm{~mm}$ & Thickness $(\mathrm{mm})$ & 2.5 & 10 & $3^{\mathrm{b}}$ & $15^{\mathrm{b}}$ & - \\
& Linear mass $(\mathrm{kg} / \mathrm{m})$ & 0.0898 & 0.0321 & 0.0297 & 0.0647 & 0.0009 \\
& Linear mass (\%) & 41.3 & 14.8 & 13.7 & 29.7 & 0.4 \\
& Density $\left(\mathrm{kg} / \mathrm{m}^{3}\right)$ & $1316 \pm 25$ & $1745 \pm 100$ & $1375 \pm 100$ & - & - \\
\hline Cable $2^{\mathrm{a}}$ & Material & PVC & PE & PE & Aluminium & - \\
$D=54 \mathrm{~mm}$ & & & & & and copper & \\
\cline { 2 - 7 } & Thickness $(\mathrm{mm})$ & $2.0^{\mathrm{b}}$ & Not measurable & $1.0^{\mathrm{b}}$ & $1.5^{\mathrm{b}}$ & - \\
& Linear mass $(\mathrm{kg} / \mathrm{m})$ & 0.649 & 0.228 & 0.662 & 0.1097 & 0.063 \\
& Linear mass (\%) & 22.8 & 8.0 & 23.3 & 38.6 & 2.2 \\
& Density $\left(\mathrm{kg} / \mathrm{m}^{3}\right)$ & $1500 \pm 30$ & $950 \pm 50$ & $1039 \pm 50$ & - & - \\
\hline
\end{tabular}

${ }^{a}$ The other components than sheath are listed just for completeness, although not studied in this work.

${ }^{\mathrm{b}}$ Measured from a photograph.

\section{Experimental}

The degradation of each of the material components was studied using simultaneous thermal analysis (STA) including thermogravimetric analysis (TGA) and differential scanning calorimetry (DSC). A small sample $(\sim 10 \mathrm{mg})$ was placed in a furnace and heated at constant rate. The sample mass and energy release were measured during the heating. The experiments were carried out both in air and nitrogen at heating rates between 2-20 K/min, using Netzsch STA 449C equipment.

Cone calorimeter experiments of Cable 1 were performed for eight $10 \mathrm{~cm}$ long samples of Cable 1 placed next to each other to construct a roughly $10 \mathrm{~cm} \times 10 \mathrm{~cm}$ exposed area. Due to the large diameter of Cable 2, it was possible to test the sheath layer alone. Radiative heat flux was $50 \mathrm{~kW} / \mathrm{m}^{2}$ and ignition by spark igniter. The heat release rate (HRR) and mass loss rate (MLR) were recorded until all the flames disappeared. Since the experimental mass data was quite noisy, the MLR was determined by fitting a piecewise continuous polynomial to the mass results and taking the MLR as a first derivative [9]. The second-order polynomials had continuous first derivative. The second-derivative discontinuities were allowed in a few locations chosen by visual inspection of the data. 


\section{Modelling}

\section{Formulation}

All the simulations were made using Fire Dynamics Simulator (FDS), version 5.5.2 [10]. In the model, the reaction rate of the pyrolysis reactions is calculated using Arrhenius equation

$$
r_{i j}=A_{i j}\left(\frac{\rho_{s, i}}{\rho_{s 0}}\right)^{N_{s, i j}} \exp \left(-\frac{E_{i j}}{R T_{s}}\right),
$$

where subscript $i$ denotes the $i^{\text {th }}$ material component and $j$ the $j^{\text {th }}$ reaction. $\rho_{s, i}$ is the solid density of the component, and $\rho_{s, 0}$ is the original density of the layer [10]. The solid phase heat conduction is solved in one dimension, according to the heat conduction equation

$$
\rho_{s} c_{s} \frac{\partial T_{s}}{\partial t}=\frac{\partial}{\partial x} k_{s} \frac{\partial T_{s}}{\partial x}+\dot{q}_{s}^{\prime \prime \prime}
$$

where the chemical source term $\dot{q}_{s}^{\prime \prime \prime}$ is

$$
\dot{q}_{s}^{\prime \prime \prime}(x)=-\rho_{s 0} \sum_{i=1}^{N_{m}} \sum_{j=1}^{N_{r}} r_{i j}(x) H_{r, i j} .
$$

A mixture fraction based combustion model was used in the Cone calorimeter simulations.

\section{Models of the Experiments}

A simple model of the TGA experiment in Nitrogen atmosphere was created. The gas phase heat and mass transport were neglected in the model and the experiment was assumed to be 0-dimensional, in which case the dimensions of the simulation domain do not affect the results. The bottom of the domain was assigned with the sample material and the side walls and ceiling were heated according to the specified heating rate. As the TGA experiments were carried out for each component separately, the model included just one homogenous layer of material.

The Cone calorimeter model had dimensions of $30 \times 30 \times 40 \mathrm{~cm}^{3}$. The sample $\left(10 \times 10 \mathrm{~cm}^{2}\right)$ was placed in the middle of the bottom boundary and all the other walls were open. The computational mesh was extremely coarse $(10 \mathrm{~cm})$. A refinement of the mesh was not found to change the results significantly at an external heat flux of $50 \mathrm{~kW} / \mathrm{m}^{2}$, but the computing time of the estimation process increased substantially. It is clear that a computation with such a coarse mesh cannot capture the details of the flame in the real Cone calorimeter experiment. However, it can provide an effective description of the flame heat flux to the sample surface because the combustion model burns most of the fuel within the one or two $10 \mathrm{~cm}$ cells above the sample, and because the source term of the gas phase radiation transport equation includes a specified fraction (usually 0.35 ) of the local heat release rate. The spark igniter was not included in the model because the ignition happens as soon as the fuel meets oxygen.

Cable 1 was modelled as a complete cable, neglecting the small amount of additional plastics. The approximation of Cable 1 structure as a planar surface is illustrated in Fig. 1. The first and third layers consist of cable sheath material. The inner layer is a homogenous mixture of the insulation and filler materials. Conductors are not combustible and thus neglected in the model for simplicity and to save computational time in large scale simulations. According our previous simulations, the effect of the conductor on the model performance is not significant. The properties of the $2 \mathrm{~cm}$ thick backing layer were $\rho=800 \mathrm{~kg} / \mathrm{m}^{3}, k_{s}=0.1 \mathrm{~W} / \mathrm{m} \cdot \mathrm{K}$ and $c_{s}=1 \mathrm{~kJ} / \mathrm{kg} \cdot \mathrm{K}$. Cable 2 model included only one layer of sheath and the backing. 


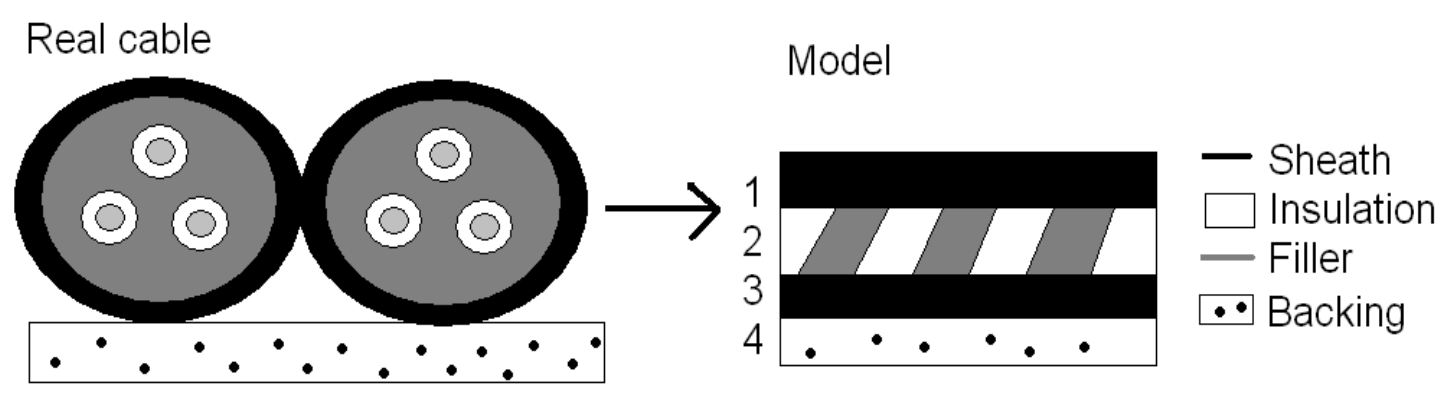

Fig. 1. Principle of creating FDS model of electrical cables in the cone calorimeter.

\section{Model Parameters}

The reaction rate formula in Eq. 1 contains three free parameters: $A, E$, and $N_{s}$. In this work, they are called 'kinetic parameters' as they define the reaction kinetics. The remaining free parameters are thermal conductivity $k_{s}$, specific heat capacity $c_{s}$ and the heat of reaction $H_{r}$. Other important parameters are the heat of combustion $\left(H_{c}\right)$ and surface emissivity $(\varepsilon)$. The heat of combustion is defined as the energy released per unit mass of reacting material in the gas phase combustion. Material-dependent heat of combustion was used to ensure that the correct amount of heat is released. The emissivity was assumed to be equal to surface absorptivity. These parameters are called 'thermal parameters'.

Three commonly used methods for determining the kinetic parameters from TGA data are the analytical and model-free methods and the estimation by optimization. When estimating the parameters by optimization, a model with free parameters is fitted to the experimental results. This method, utilizing e.g. genetic algorithm (GA) as an optimization method, has been used in many of the recent works [4-7]. Genetic algorithms are based on the idea of survival of the fittest. Originally a random set of parameters is tested against the experiment, and the best fitting sets survive to the next iteration round. The method is effective in non-linear problems with several unknown parameters. The algorithm works well with any kind of reaction paths or parameter ranges. The drawback may be a long estimation time, and the stochastic nature of the algorithm. The number of iterations needed cannot be predicted as all the operations depend on the random numbers and probability distributions. This method can be used also for the estimation of other parameters and using other experimental results, such as Cone calorimeter. The GA parameters in this work are the same as used in Ref. [6] except for the mutation rate that was set to 0.25 .

An analytical method for the determination of kinetic parameters was introduced by McGrattan et al. [11]. It assumes that all the material components undergo parallel one-step reactions with reaction order 1 . This method has an advantage of being very fast; often just a couple of trials are needed. The parameters are calculated from a reference temperature $\left(T_{p}\right)$, reference mass loss ratio $\left(Y_{p}\right)$ and the reference mass loss rate $\left(r_{p}\right)$. The reference temperature is the reaction peak temperature of TGA gradient, and the mass values are the corresponding mass and mass gradient values. According those values, the $A$ and $E$ can be calculated as

$$
\left\{\begin{array}{l}
E=\frac{R T_{p}^{2}}{\beta} \frac{r_{p}}{Y_{p}} \\
A=\frac{r_{p}}{Y_{p}} \exp \left(\frac{E}{R T_{p}}\right)
\end{array} .\right.
$$

The model-free methods are based on simple analytical calculations. Equation 1 can be written as

$$
\ln \left(r_{i j}\right)-N_{s} \ln \left(\frac{\rho_{s, i}}{\rho_{s 0}}\right)=\ln (A)-\frac{E}{R T_{s}}
$$


The reaction order $N_{\mathrm{s}}$ is a modelling choice. After choosing $N_{\mathrm{s}}$, the unknown parameters, $A$ and $E$ can be determined by fitting a straight line to the plot of the left hand side against $1 / T_{s}$. This method is relatively fast and does not assume anything of the reaction order. However, it is quite sensitive for the choice of the temperature area considered and the details of the fitting process. Practical aspects of model-free methods were recently discussed by Kim [12].

Thermal parameters can be either directly measured or estimated from a Cone calorimeter test. Typical measured values are the specific heat capacity and the heat of reaction that can be obtained using DSC. The measurement of thermal conductivity is possible for building materials, for instance, but unpractical for small plastic samples, such as the components of electrical cables, or materials undergoing thermal degradation in the interesting temperature range. The effective heat of combustion, derived from the Cone calorimeter results, can sometimes be used as a material property if the relative proportions of the pyrolyzing materials are known over the time of the experiment. Alternatively, the heats of combustion can be estimated like the other thermal parameters by considering the difference between the measured and simulated effective heats of combustion as one of the measures of model fitness.

\section{RESULTS AND DISCUSSION}

\section{Parallel Reactions - Model}

The TGA results of the sheath materials of Cables 1 and 2 were found to be very close to each other. Therefore, the kinetic parameters were only estimated for Cable 1 and used for the sheaths of both cables. The sheath material was assumed to be a homogenous mixture of three independent components. A parallel reaction path with free reaction orders was used. A genetic algorithm was used for the estimation. The reaction path and the kinetic parameters are shown in Fig. 2 and the comparison of experimental and simulated TGA results in Fig. 3. The results fit slightly better for Cable 1, for which the parameters were estimated, but the difference to Cable 2 is not large. The reaction paths and kinetic parameters of the Cable 1 filler and insulation materials are shown in Figs. 4 and 5, respectively.

\begin{tabular}{|c|c|}
\hline $\begin{array}{l}\text { (56\%) Component } 1 \\
A=7.56 \cdot 10^{13}, E=1.73 \cdot 10^{5}, N_{s}=0.96\end{array}$ & $\left\{\begin{array}{l}(65 \%) \mathrm{HCl} \\
(35 \%) \text { Fuel }\end{array}\right.$ \\
\hline (33\%) Component 2 & $\int(67 \%)$ Char \\
\hline$A=6.50 \cdot 10^{19}, E=2.95 \cdot 10^{5}, N_{s}=2.71$ & $\{(33 \%)$ Fuel \\
\hline (11\%) Component 3 & $\int(31 \%)$ Char \\
\hline$A=5.43 \cdot 10^{11}, E=2.40 \cdot 10^{5}, N_{s}=2.48$ & $\{(69 \%)$ Fuel \\
\hline
\end{tabular}

Fig. 2. Parallel model reaction path and kinetic parameters for the cable sheath. $A$ in $\mathrm{s}^{-1}$ and $E$ in $\mathrm{kJ} / \mathrm{kmol}$.

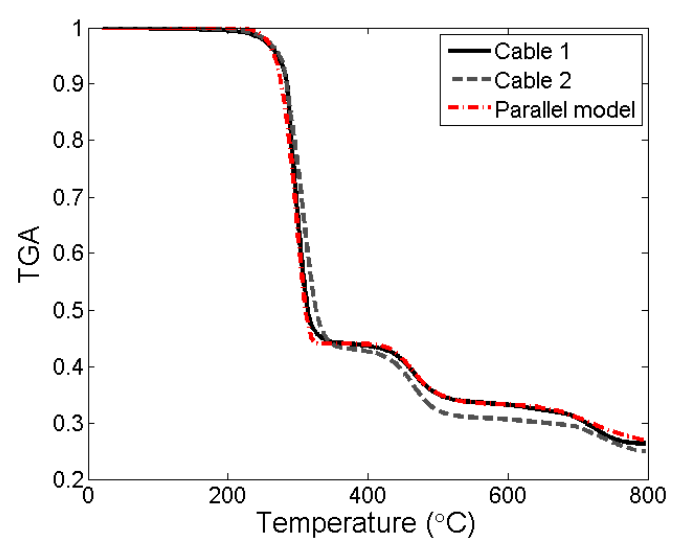

(a)

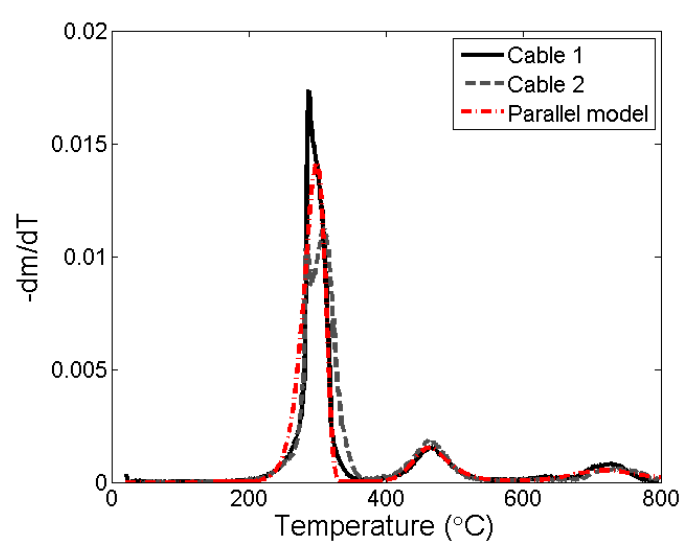

(b)

Fig. 3. TGA results $(10 \mathrm{~K} / \mathrm{min})$ for cable sheaths and FDS fit: (a) TGA; (b) Gradient of TGA. 


\begin{tabular}{|c|c|}
\hline (49.5\%) Component 1 & $\mathrm{HCl}$ \\
\hline$A=1.77 \cdot 10^{12}, E=1.51 \cdot 10^{5}, N_{s}=1.69$ & \\
\hline (50.5 \%) Component 2 & $((75 \%)$ Component $3 \longrightarrow$ \\
\hline$A=3.12 \cdot 10^{14}, E=2.32 \cdot 10^{5}, N_{s}=3.0$ & $\{$ (25 \%) Fuel \\
\hline$\rightarrow$ Component 3 & $\int(77 \%)$ Char \\
\hline$A=1.61 \cdot 10^{6}, E=1.59 \cdot 10^{5}, N_{s}=2.62$ & $\{(23 \%)$ Fuel \\
\hline
\end{tabular}

Fig. 4. Reaction path and kinetic parameters for the insulating material. $A$ in s ${ }^{-1}$ and $E$ in $\mathrm{kJ} / \mathrm{kmol}$.

\begin{tabular}{|c|c|}
\hline $\begin{array}{l}\text { Component } 1 \\
A=5.28 \cdot 10^{9}, E=1.31 \cdot 10^{5}, N_{s}=0.77\end{array}$ & $\left\{\begin{array}{l}(75 \%) \text { Component } 2 \longrightarrow \\
(25 \%) \text { Fuel }\end{array}\right.$ \\
\hline $\begin{array}{l}\longrightarrow \text { Component } 2 \\
A=9.02 \cdot 10^{7}, E=1.96 \cdot 10^{5}, N_{s}=2.46\end{array}$ & $\left\{\begin{array}{l}(56 \%) \text { Char } \\
(44 \%) \text { Fuel }\end{array}\right.$ \\
\hline
\end{tabular}

Fig. 5. Reaction path and kinetic parameters for the filler. $A$ in $\mathrm{s}^{-1}$ and $E$ in $\mathrm{kJ} / \mathrm{kmol}$.

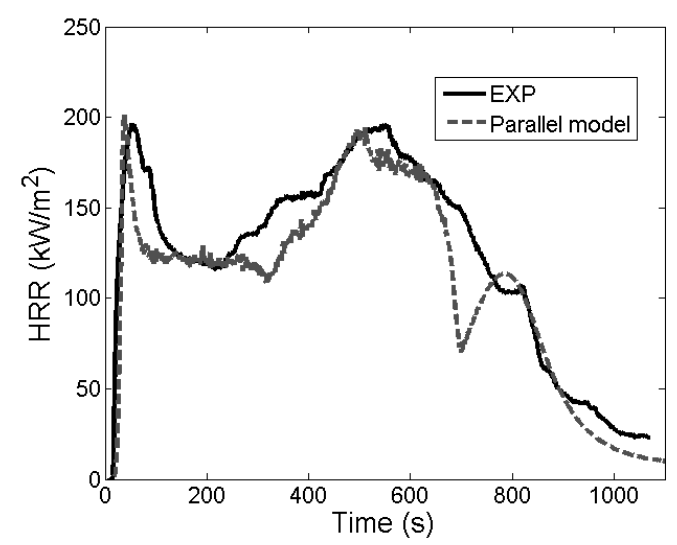

(a)

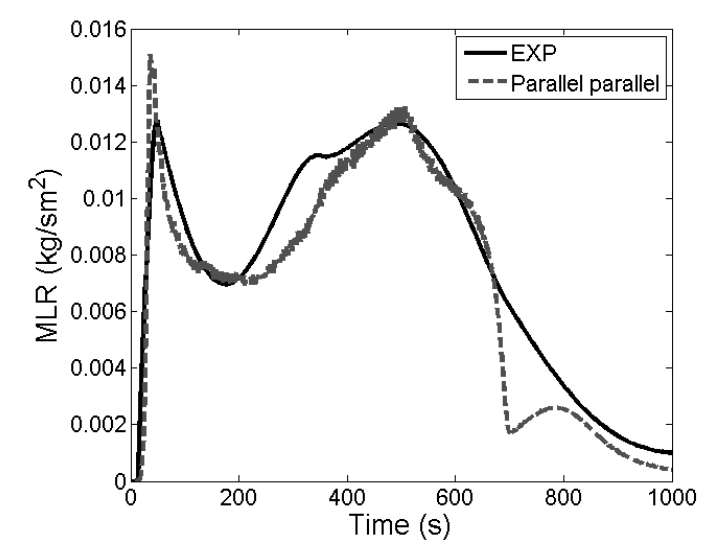

(b)

Fig. 6. Comparison of experimental and simulated Cone calorimeter results of Cable 1 at $50 \mathrm{~kW} / \mathrm{m}^{2}$ : (a) heat release rate; (b) mass loss rate.

The thermal parameters were estimated from the Cone calorimeter experiments. The emissivities of the initial material components were set to 1.0, but non-unity emissivities were allowed for the chars. This choice was made because earlier sensitivity studies had shown that the results are sensitive to the emissivity of char but not to the emissivity of the virgin material. Besides, the virgin emissivity only plays a role during the short time before the ignition. As the conductivities and the specific heats were treated as constants over temperature, the estimated values must be treated as averages over corresponding temperature ranges. The middle layer of Cable 1 is a mixture of $48.1 \%$ insulator and $51.9 \%$ filler. The layer thicknesses from first to last are $2.73 \mathrm{~mm}, 3.2 \mathrm{~mm}$ and $2.73 \mathrm{~mm}$. A comparison of simulated and measured HRR and MLR is shown in Fig. 6. The model predicts very accurately both the ignition time and shapes of the two peaks in the curves. Including data for different radiation levels would probably reduce the model fitness into a single curve but improve the parameter generality. Inclusion of surface temperature measurement, as in [7], would add another dimension to the fitness assessment. However, performing such measurements for thermoplastic samples with complex structure may be challenging.

For Cable 2, only the sheath layer (2.9 mm thick) was modelled. A comparison of the experimental and model HRR and MLR is shown in Fig. 7. Again, ignition time is accurately predicted and the overall shapes of the curves are satisfactory, although not as accurate as for Cable 1. The thermal parameters are listed in Table 2. Some of the conductivity and heat of combustion values are equal to the lower or upper 
bounds of the corresponding estimation ranges. This means that the optimization algorithm could not find a good agreement within the estimation range, and it might be possible to obtain a better fitting model with a wider estimation range. It is interesting that even though the reaction paths and kinetic parameters were identical for the two cables, the thermal parameters resulting from the estimation process turned out be quite different. The most significant difference can be found for $H_{\mathrm{c}}$ of the first component of the sheath. For Cable 1, at $35 \%$ fuel yield it is $40 \mathrm{MJ} / \mathrm{kg}$ while for Cable 2 with the same fuel yield only $15 \mathrm{MJ} / \mathrm{kg}$.

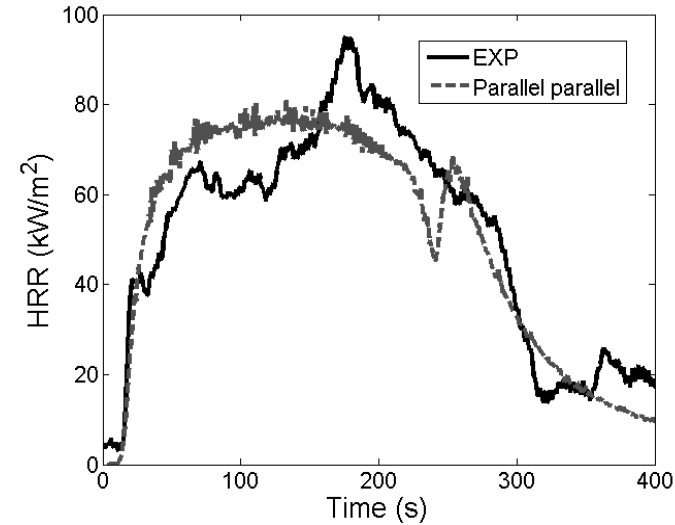

(a)

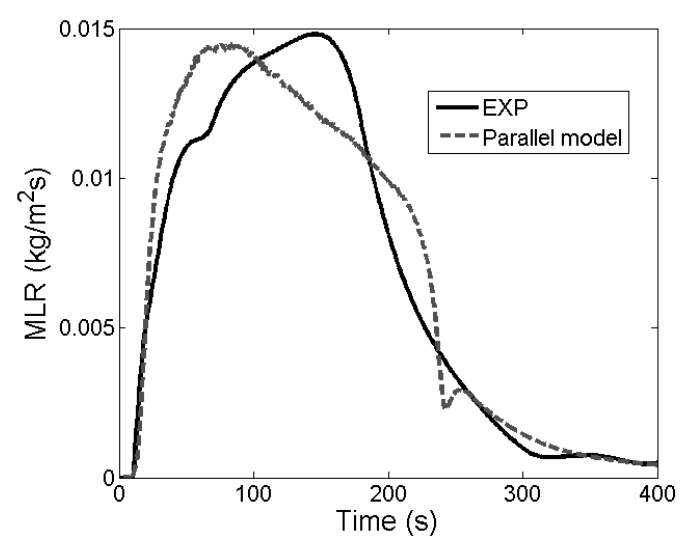

(b)

Fig. 7. Comparison of experimental and simulated Cone calorimeter results of sheath of Cable 2 at $50 \mathrm{~kW} / \mathrm{m}^{2}$ : (a) heat release rate; (b) mass loss rate.

Table 2. Thermal parameters of the cable models. 'Sheath $(\mathrm{N}=1)$ ' of Cable 1 is related to the section Effect of the Kinetic Parameters. The emissivities for Components 1-3 are all 1.0.

\begin{tabular}{|c|c|c|c|c|c|c|c|c|}
\hline \multirow[b]{3}{*}{ Cable 1} & \multicolumn{4}{|c|}{ Component 1} & \multicolumn{4}{|c|}{ Component 2} \\
\hline & $\begin{array}{c}k_{\mathrm{s}} \\
(\mathrm{W} / \mathrm{m} \cdot \mathrm{K})\end{array}$ & $\begin{array}{c}c_{\mathrm{s}} \\
(\mathrm{kJ} / \mathrm{kg} \cdot \mathrm{K})\end{array}$ & $\begin{array}{c}H_{\mathrm{r}} \\
(\mathrm{kJ} / \mathrm{kg})\end{array}$ & $\begin{array}{c}H_{\mathrm{c}} \\
(\mathrm{MJ} / \mathrm{kg})\end{array}$ & $\begin{array}{c}k_{\mathrm{s}} \\
(\mathrm{W} / \mathrm{m} \cdot \mathrm{K})\end{array}$ & $\begin{array}{c}c_{\mathrm{s}} \\
(\mathrm{kJ} / \mathrm{kg} \cdot \mathrm{K})\end{array}$ & $\begin{array}{c}H_{\mathrm{r}} \\
(\mathrm{kJ} / \mathrm{kg})\end{array}$ & $\begin{array}{c}H_{\mathrm{c}} \\
(\mathrm{MJ} / \mathrm{kg})\end{array}$ \\
\hline & & & & & & & & \\
\hline Sheath ( $\mathrm{N}$ free) & 0.25 & 2.0 & 800 & 40 & 0.15 & 2.8 & 700 & 45 \\
\hline Sheath $(\mathrm{N}=1)$ & 0.14 & 3.5 & 1110 & 45 & $0.1^{\mathrm{a}}$ & 0.8 & 1760 & $45^{\mathrm{b}}$ \\
\hline Insulation & 0.77 & 3.3 & 450 & - & 0.4 & 2.5 & 300 & $45^{\mathrm{b}}$ \\
\hline Filler & 0.65 & 2.5 & 800 & 30 & 0.45 & 0.81 & 300 & 40 \\
\hline \multicolumn{9}{|l|}{ Cable 2} \\
\hline \multirow[t]{3}{*}{ Sheath } & $0.1^{\mathrm{a}}$ & 1.5 & 1630 & 15 & 0.26 & 1.6 & 740 & 23.9 \\
\hline & \multicolumn{4}{|c|}{ Component 3} & \multicolumn{4}{|c|}{ Residue } \\
\hline & $\begin{array}{c}k_{\mathrm{s}} \\
(\mathrm{W} / \mathrm{m} \cdot \mathrm{K})\end{array}$ & $\begin{array}{c}c_{\mathrm{s}} \\
(\mathrm{kJ} / \mathrm{kg} \cdot \mathrm{K})\end{array}$ & $\begin{array}{c}H_{\mathrm{r}} \\
(\mathrm{kJ} / \mathrm{kg})\end{array}$ & $\begin{array}{c}H_{\mathrm{c}} \\
(\mathrm{MJ} / \mathrm{kg})\end{array}$ & $\begin{array}{c}k_{\mathrm{s}} \\
(\mathrm{W} / \mathrm{m} \cdot \mathrm{K})\end{array}$ & $\begin{array}{c}c_{\mathrm{s}} \\
(\mathrm{kJ} / \mathrm{kg} \cdot \mathrm{K})\end{array}$ & & $\varepsilon$ \\
\hline Cable 1 & & & & & & & & \\
\hline Sheath ( $\mathrm{N}$ free) & 0.15 & 2.09 & 700 & $40^{\mathrm{b}}$ & 0.9 & 2.0 & & 1.0 \\
\hline Sheath $(\mathrm{N}=1)$ & 0.42 & 0.8 & 950 & $45^{\mathrm{b}}$ & $0.8^{\mathrm{b}}$ & 2.0 & & 0.99 \\
\hline Insulation & 0.79 & 0.8 & 300 & 40 & 0.67 & 1.3 & & 1.0 \\
\hline Filler & - & - & - & - & 0.25 & 1.3 & & 1.0 \\
\hline Cable 2 & & & & & & & & \\
\hline Sheath & 0.21 & 1.37 & 1860 & 27.8 & 0.79 & 2.0 & & 0.98 \\
\hline
\end{tabular}

${ }^{\mathrm{a}}$ At lower bound of estimation range.

${ }^{b}$ At upper bound of estimation range. 


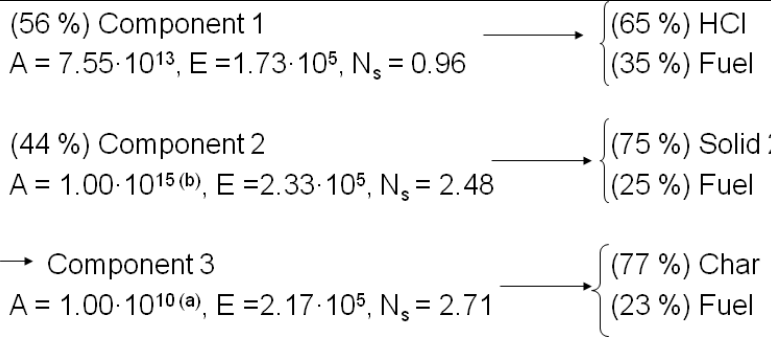

Fig. 8. Consecutive model reaction path and kinetic parameters for the cable sheath; ${ }^{(a)}$ at lower bound of the estimation range; ${ }^{(b)}$ at upper bound of estimation range.

\section{Effect of the Reaction Scheme}

The parallel model the reaction path describing the sheath pyrolysis consists of three parallel reactions, which is the simplest possible model being able to reproduce the three distinct reactions observed in the TGA curve. In the absence of information about the true chemical formulations and reactions, which is often the case in fire modelling, the reaction path is modeller's choice. The only evidence for or against the chosen scheme comes from the fitting process. Alternative schemes, such as a consecutive reaction path, must be evaluated based on their fitting capability and the credibility of the best-fitting model parameters. A consecutive reaction path was therefore applied to the sheath reactions, yielding the kinetic parameters shown in Fig. 8. The estimated values for the pre-exponential factors of components 2 and 3 correspond to the upper and lower bounds of the estimation range, indicating that the algorithm could not find satisfactory fit in the range of these parameters. For better agreement with consecutive reactions, the range of these parameters should be extended. A comparison of the parallel and consecutive model predictions of TGA at $10 \mathrm{~K} / \mathrm{min}$ heating rate is shown in Figs. 9a-b. Both reaction paths can accurately predict the experimental results. The other model parameters were the same for both models, as listed in Table 2 . The effect of the reaction path on the simulated cone calorimeter results is shown in Figs. 9c-f. Even though the TGA curves are quite close to each other, the cone calorimeter results differ significantly. In the consecutive reaction path, the third reaction is limited by the second one. Parallel reaction path does not have this limitation and this could explain the differences in the cone calorimeter results. For Cable 1, the consecutive reaction scheme yields lower heat release and mass loss rates and longer extinction times than the parallel scheme. The differences are in the same direction but less significant for the sheath of Cable 2.

In theory, the degradation of rigid PVC could be modelled as a two-stage process: the first releasing $\mathrm{HCl}$ and the second producing combustible fuel vapour and residue. Flexible PVC contains softeners, such as phthalates, with degradation products such as benzene, naphthalene and anthracene that may be combustible and must be considered in the pyrolysis modelling. In the presence of Oxygen and heat these compounds can burn, having a heat of combustion over $40 \mathrm{MJ} / \mathrm{kg}$ [13]. In the pyrolysis modelling, the release of combustible products is considered by specifying a non-zero fuel yield for the first reaction of PVC. In the most accurate model for the cable sheaths, the fuel yield of the first reaction was $35 \%$. The effect of this parameter for the HRR prediction is demonstrated in Fig. 10 showing the HRR results for both cables at three different fuel yields $0 \%, 15 \%$ and $35 \%$ of the first reaction step. The smaller-than-optimal yield of fuel can, to some extent, be compensated by adjusting the heat of combustion of the corresponding material. The values should however be chosen from a reasonable range, i.e. smaller or equal to $50 \mathrm{MJ} / \mathrm{kg}$.

In the parallel model, both solid components produce independently fuel and char. One could also choose the mass fractions so that only the second solid reaction produces char, and the other one fuel. The cone calorimeter results are not sensitive to this choice for any of the cable models. 


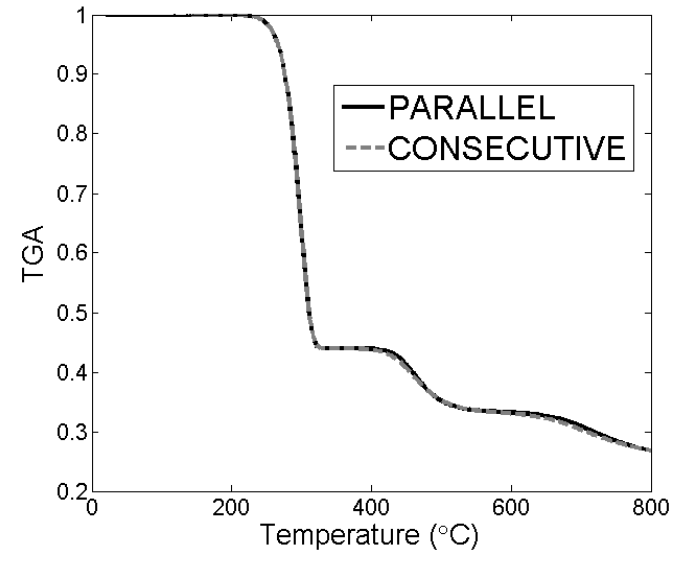

(a)

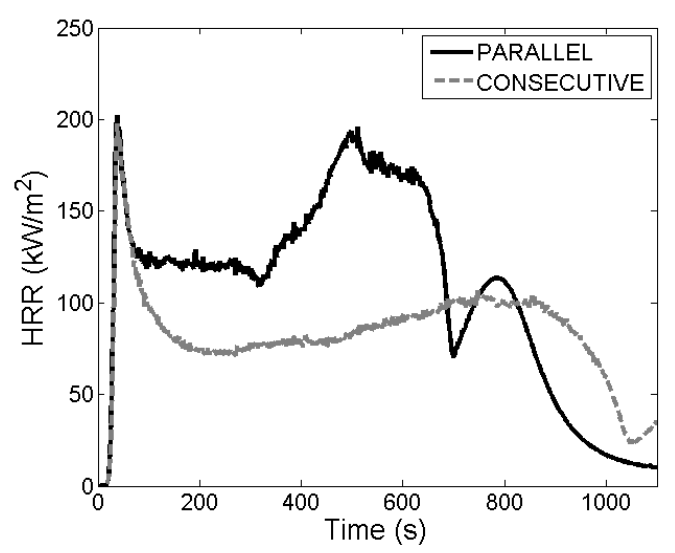

(c)

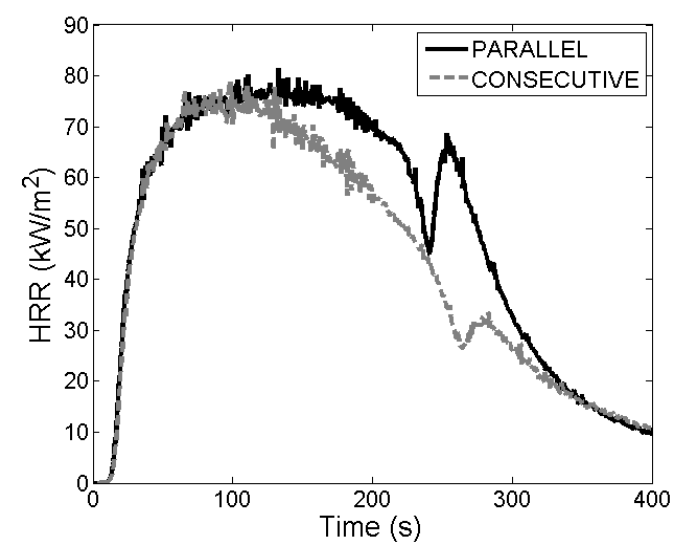

(e)

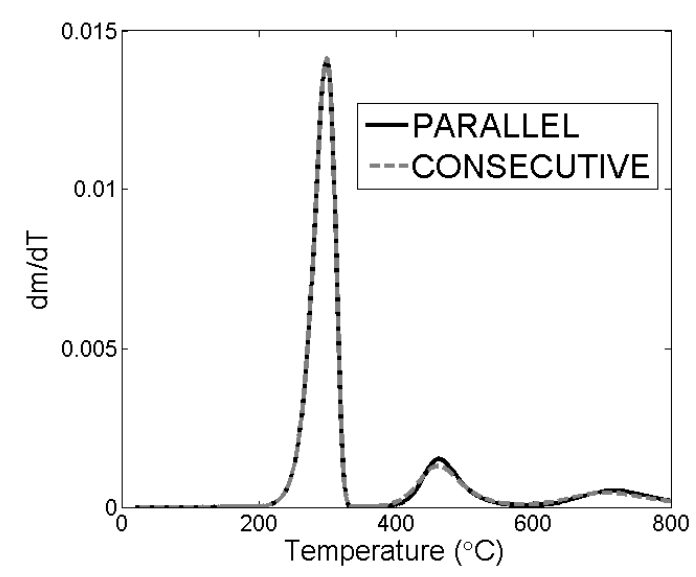

(b)

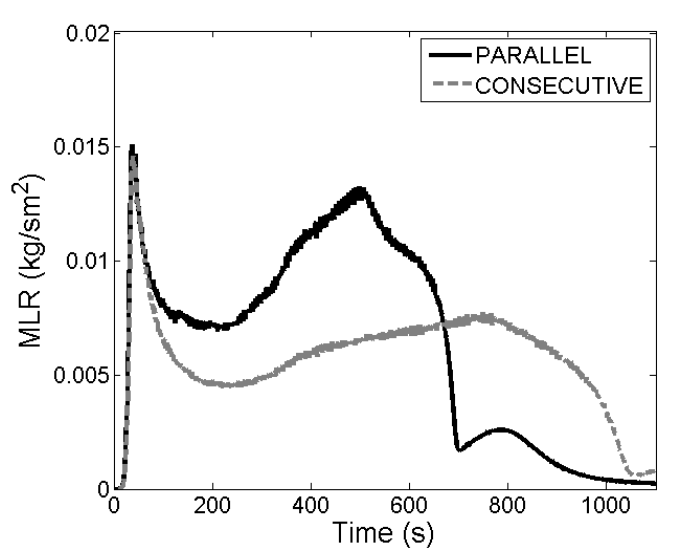

(d)

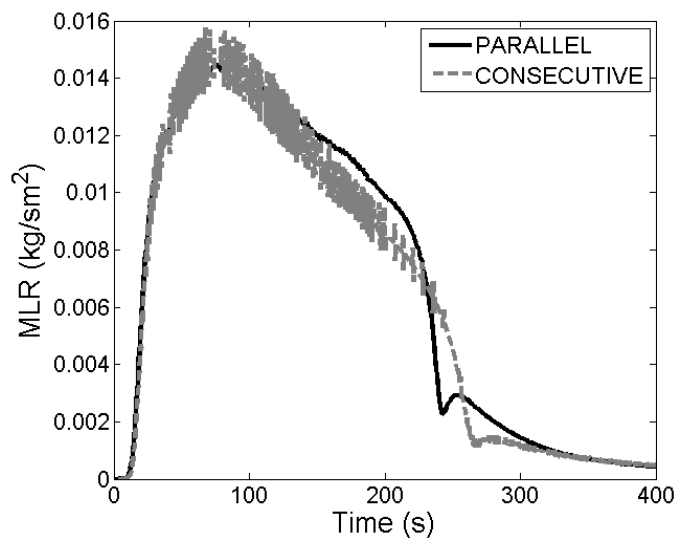

(f)

Fig. 9. Sensitivity of the cable pyrolysis for the reaction path in TGA (a and b) and cone calorimeter (c-f): (c) HRR of Cable 1; (d) MLR of Cable 1; (e) HRR of Cable 2 sheath; (f) MLR of Cable 2 sheath. 


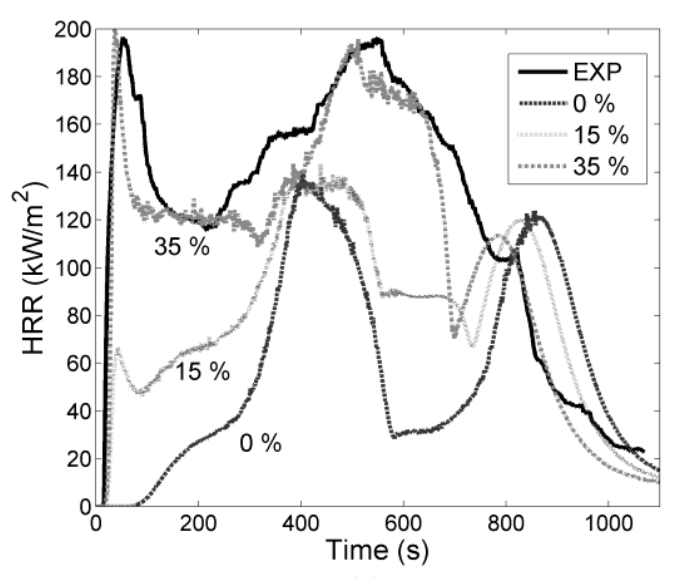

(a)

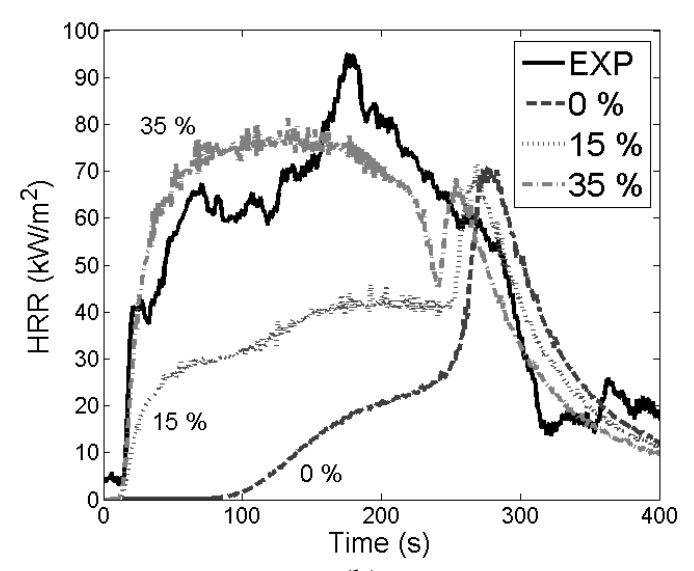

(b)

Fig. 10. Effect of first reaction fuel yield at $50 \mathrm{~K} / \mathrm{min}$ : (a) Cable 1; (b) Cable 2 sheath.

\section{Effect of the Kinetic Parameters}

Due to the so-called 'compensation effect', the values of $A$ and $E$ are usually not important just by themselves, but their ratio is significant [14]. Many different sets of kinetic parameters can thus produce equally accurate prediction for TGA results. Two different sets of kinetic parameters were estimated with constraint $N_{s}=1$. One was estimated using the genetic algorithm (GA) and another one using the analytical method. The reaction paths were parallel and the differences were only allowed in the kinetic parameters and fuel allocation of the components. The results are shown in Fig. 11 and kinetic parameters listed in Table 3. The TGA predictions are quite similar with the two sets of parameters. Using the thermal parameters listed in Table 2, the cone calorimeter results do not show any significant difference either, indicating that there is no preference over one of the estimation methods. Due to the use of a non-optimized set of thermal parameters, neither of the results shown in Figs. 11c-d are close to the experimental result, though. Both estimation methods have their advantages. The GA takes a longer time than the analytical method, but is more flexible for the changes in the reaction path and the reaction order. The analytical method provides fast results, but the model has to be limited to parallel reaction path with reaction order 1 .

A comparison between Table 3 and Fig. 2 shows that the mass allocations between components 2 and 3 have been exchanged. The integrated mass loss and heat release are still quite close to each other due to the different fuel yields. This peculiarity is caused by the nature of the parallel reaction scheme, for which the assignment of reactions between the reactions observed in TGA by the stochastic optimization cannot be pre-determined, if the parameter ranges are wide enough. This should be kept in mind when interpreting the results of the stochastic optimization methods.

Table 3. Kinetic parameters with $N_{\mathrm{s}}=1$.

\begin{tabular}{|lccc|}
\hline & $\boldsymbol{A}\left(\mathbf{s}^{-1}\right)$ & $\boldsymbol{E}(\mathbf{k J} / \mathbf{k m o l})$ & Residue yield \\
\hline Method: GA & & & \\
Component 1 (56 \%) & $1.08 \times 10^{15}$ & $1.85 \times 10^{5}$ & $0 \%$ \\
Component 2 (11 \%) & $5.93 \times 10^{11}$ & $1.99 \times 10^{5}$ & $6 \%$ \\
Component 3 (33\%) & $1.08 \times 10^{12}$ & $2.73 \times 10^{5}$ & $83 \%$ \\
\hline Method: Analytical & & & \\
Component 1 (56 \%) & $9.80 \times 10^{18}$ & $2.24 \times 10^{5}$ & $0 \%$ \\
Component 2 (10\%) & $3.40 \times 10^{36}$ & $5.40 \times 10^{5}$ & $0 \%$ \\
Component 3 (34 \%) & $1.67 \times 10^{9}$ & $2.21 \times 10^{5}$ & $79 \%$ \\
\hline
\end{tabular}




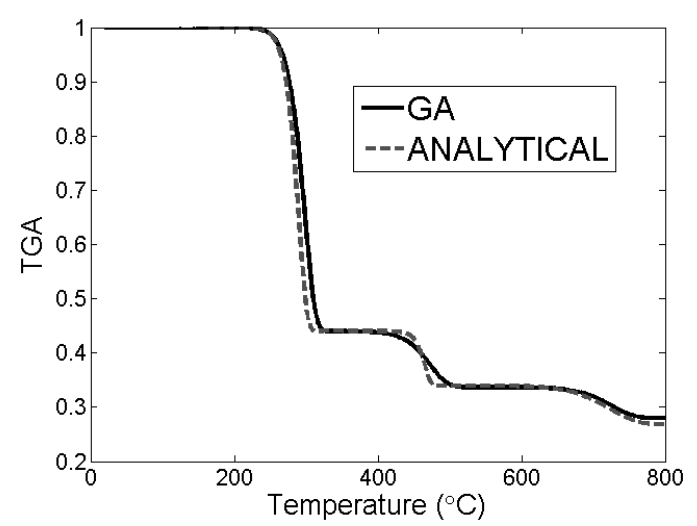

(a)

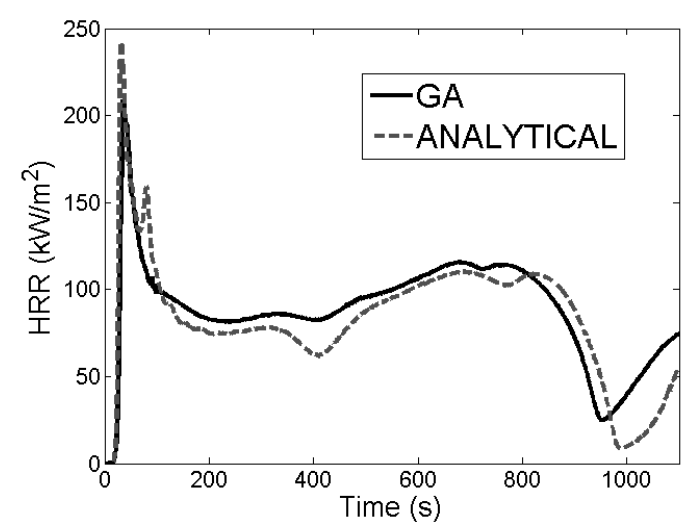

(c)

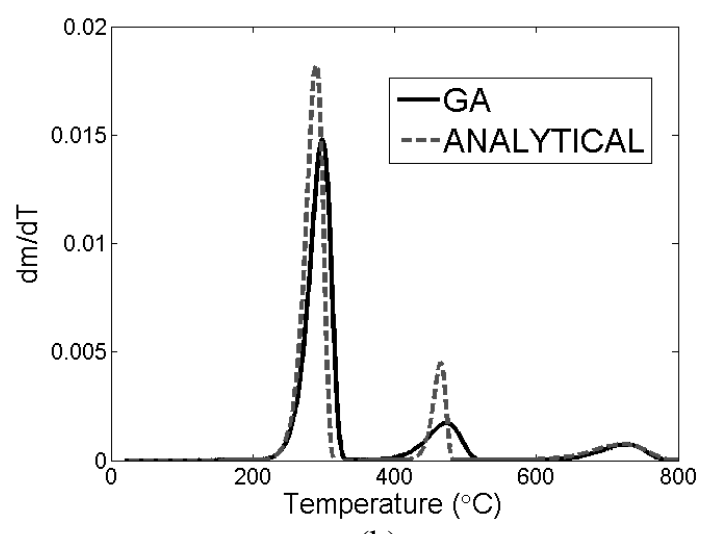

(b)

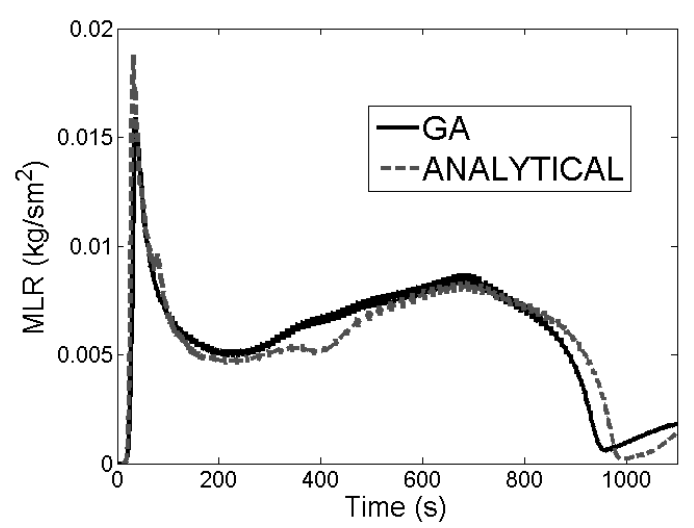

(d)

Fig. 11. Sensitivity of the simulation results to different sets of parameters for Cable 1: (a) TGA at $10 \mathrm{~K} / \mathrm{min}$; (b) gradient of TGA at $10 \mathrm{~K} / \mathrm{min}$; (c) HRR at $50 \mathrm{~kW} / \mathrm{m}^{2}$; (d) MLR at $50 \mathrm{~kW} / \mathrm{m}^{2}$.

The reaction order affects the sharpness of the TGA curve. In Fig. 12, models with two different reaction orders are compared. For ' $\mathrm{N}$ free', the kinetic parameters were those shown in Fig. 2 and for ' $\mathrm{N}=1$ ', the parameters estimated by GA, shown in Table 3 were used. Thermal parameters were the same in both models (Table 2). TGA curves (Fig. 12a-b) are very close to each other, but the cone results (Fig. 12c-d) show more differences. Both heat release and mass loss rates are higher when $N_{\mathrm{s}}$ is freely chosen. The magnitude of the differences is somewhat surprising, considering the very close match in TGA. The ' $\mathrm{N}=1$ ' model gives lower HRR than the version with free $N$, even though the heat of combustion and all the other thermal parameters are the same. The explanation can be found in the different sources of fuel in these two models, as indicated by Fig. 2 and Table 3. The total fuel yields are the same for the two models (otherwise TGA curves would be different) but the heats of combustion of the components 2 and 3 are different (45 and $40 \mathrm{MJ} / \mathrm{kg}$, respectively, Table 2). 


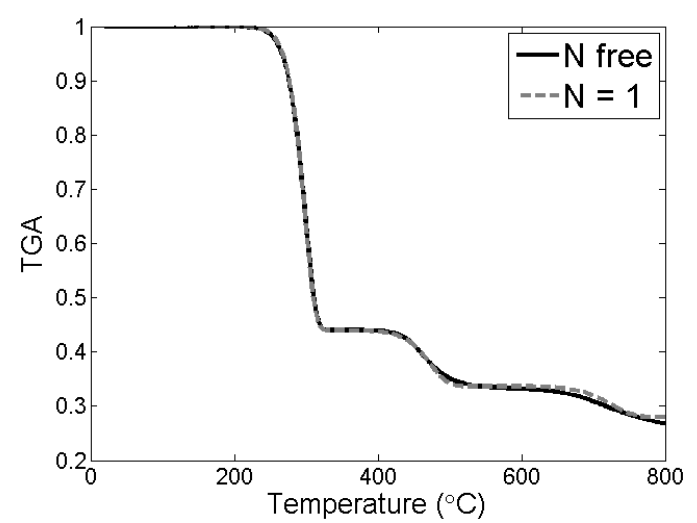

(a)

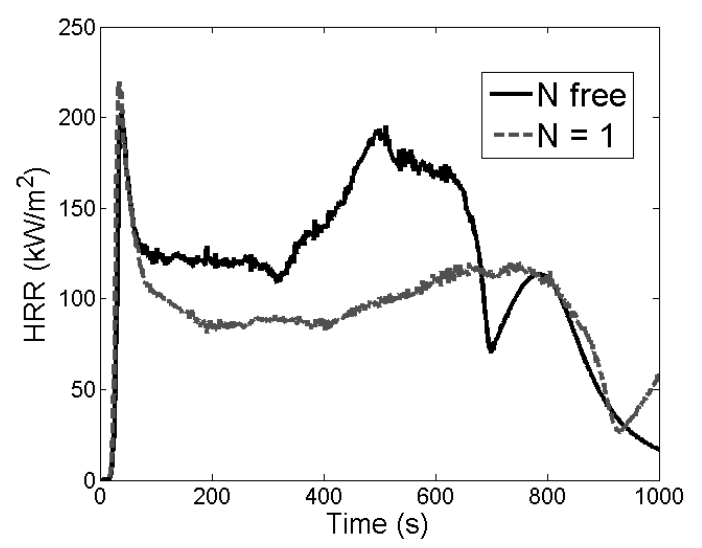

(c)

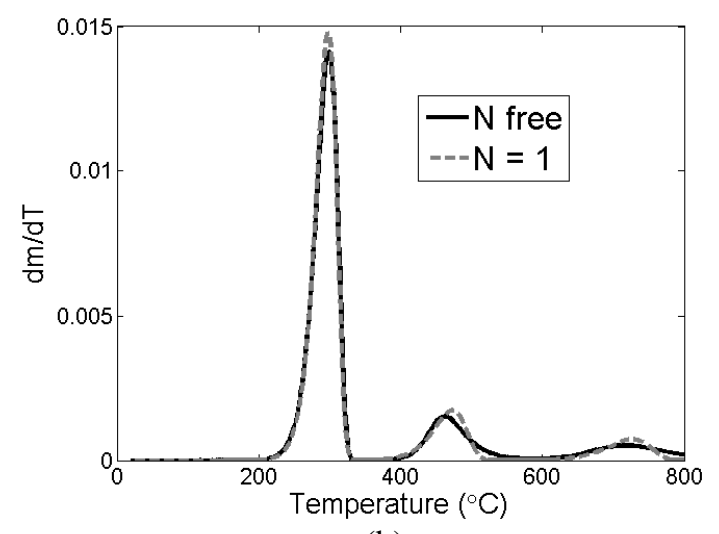

(b)

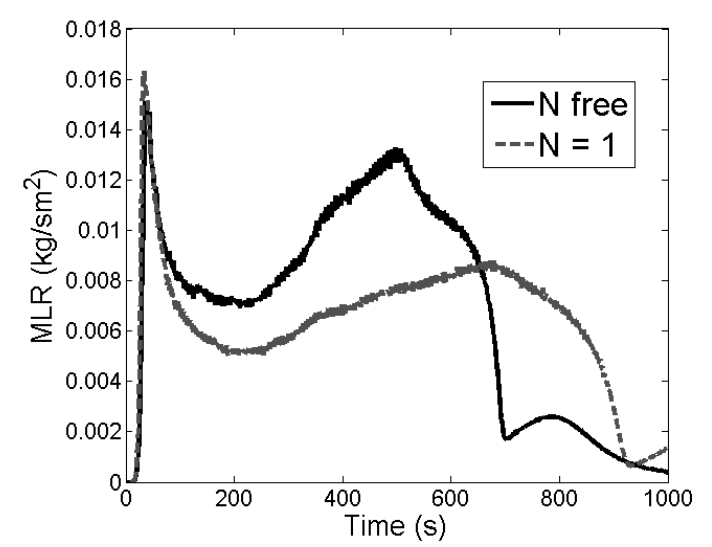

(d)

Fig. 12. Comparison of results with different reaction orders for Cable 1: (a) TGA at $10 \mathrm{~K} / \mathrm{min}$; (b) gradient of TGA at $10 \mathrm{~K} / \mathrm{min} ;$ (c) heat release rate at $50 \mathrm{~kW} / \mathrm{m}^{2}$; (d) mass loss rate at $50 \mathrm{~kW} / \mathrm{m}^{2}$.

The relatively strong effect that the kinetic parameters have on the cone calorimeter simulation can be 'compensated' by adjusting other parameters. When the thermal parameters for sheath were estimated separately for the both kinetic schemes, ' $\mathrm{N}$ free' and ' $\mathrm{N}=1$ ', the HRR and MLR predictions (Fig. 13) come very close to each other and closer to the experimental curve. The parameter values, in turn, are significantly different. They are listed in Table 2 as 'Cable 1 Sheath $(N=1)$ '. The greatest differences are found in the specific heat capacities of the initially existing material components (i.e. not residue), the heat of reaction of the second component and the thermal conductivity of the third component.

From a theoretical viewpoint, it may be discomforting to see that the thermal parameters can 'compensate' for the choices concerning the reaction scheme or the values of the kinetic coefficients. This problem should be examined from the viewpoint of the experimental and model uncertainty: If one wants to test the capability of a model to explain observed experimental evidence, one must also take into account the uncertainty associated with the experimental data and conditions, and the model input parameters. If the model can or cannot be fit to the test data within the given uncertainty bounds of the thermal parameters, that is all we can say. Of course, if one can directly measure any of the parameters with a sufficient accuracy, the size of the parameter space would be reduced, and the weight of the given scenario increased as an evidence of the model validity. Direct measurements of the properties are therefore highly recommended whenever possible. 

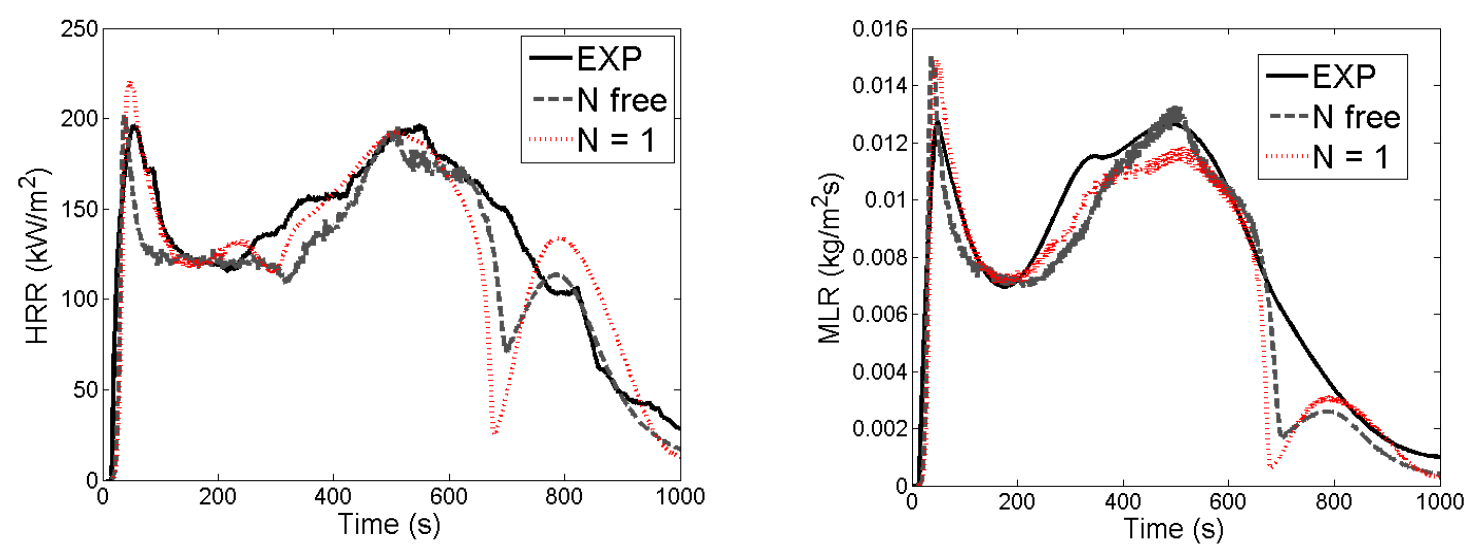

Fig. 13. Cone calorimeter results at $50 \mathrm{~kW} / \mathrm{m}^{2}$ with separately estimated thermal parameters for the two sets of kinetic parameters: (a) heat release rate; (b) mass loss rate.

\section{CONCLUSIONS}

The effects of the modelling decisions and methods on the pyrolysis modelling of two PVC cables were studied. The kinetic and thermal parameters were estimated from the TGA and cone calorimeter experiments. The TGA results of the cable sheaths were so close to each other that the same kinetic parameters were used for both cables. With three structural components describing the structure of the complete cable (sheath, insulation and filler) and two to three material components for each structural components, the estimation algorithm was able to find a set of parameters that accurately reproduced the mass loss and heat release rate curves at one radiation level.

The effect of the reaction path was studied by comparing the results obtained with parallel and consecutive reaction schemes. The effect on the TGA results was shown to be very small. However, a substantial effect was observed in the cone calorimeter results, where the consecutive scheme produced significantly lower heat release and mass loss rates. The plasticizers that are used in the production of flexible PVC were found to have a strong effect on the early part of the HRR curves. These additives can make up 30-40 wt. \% of the flexible PVC, and should therefore be taken into account in the pyrolysis model as a non-zero fuel yield for the first degradation reaction. The exact allocation of the fuel between the components was found to be unimportant, as long as the correct yields of fuel and residue were retained.

When first-order reactions were assumed and two sets of parameters estimated, no significant differences were found. Both estimation methods accurately reproduced the TGA curve. The different values of reaction order made more difference. The TGA predictions were almost equal, but the heat release and mass loss were greatly reduced when the reaction order was forced to one without estimating a separate set of thermal parameters. When the separate thermal parameters were estimated for the two different sets of kinetic parameters, equally good fits to the experimental data were again achieved, but the estimated values of the thermal parameters were very different.

The reaction path, estimation method and the parameter sets can be chosen in many ways when estimating the pyrolysis model parameters from the cone calorimeter results. Thermal parameters can, to some extent, compensate the choices made for the kinetic model. Nothing implies that one way to make the choice would be better than another. This is a topic that requires more research and discussion. However, the results demonstrate that the thermal parameters estimated for one kinetic model should not be used for another, unless the difference between the kinetic models considers only fuel yields or different pairs of $A$ and $E$ with same $N_{\mathrm{s}}$. It is very important to check the model behaviour when changing the model details or the simulation code version. Also, the universality of the thermal parameters could be improved by considering a wider set of experimental data during the parameter estimation process, such as sample temperatures, different heat flux levels and different atmospheres. 


\section{ACKNOWLEDGEMENTS}

This work has been partially funded by the State Nuclear Waste Management Fund (VYR). Authors would like to thank Tuula Leskelä from Aalto University School of Science and Technology for the thermogravimetric experiments, and Konsta Taimisalo and Johan Mangs from VTT for help when conducting cone calorimeter experiments.

\section{REFERENCES}

[1] DeLassus, P.T., and Whiteman, N.F., "Physical and Mechanical Properties of Some Important Polymers," Polymer Handbook (4th ed.), Brandrup, J., Immergut, E.,H. Grulke, E.A., Abe, A., Bloch, D.R. (ed. ) Wiley, New York, 1999, pp. 159-169.

[2] Papazoglou, E., Flame Retardants for Plastics. Handbook of building materials for fire protection, Harper, C.A. (ed.), McGraw-Hill, New York, NY, 2004. pp. 4.1-4.88.

[3] Marcilla, A., and Beltrán, M., (1995) Thermogravimetric kinetic study of poly(vinyl Chloride) pyrolysis. Polymer Degradation and Stability 48: 219-229. http://dx.doi.org/10.1016/0141$\underline{3910(95) 00050-\mathrm{V}}$

[4] Lautenberger, C., Rein, G., and Fernandez-Pello, C., (2006). The application of a genetic algorithm to estimate material properties for fire modeling from bench-scale fire test data. Fire Safety Journal 41: 204-214. http://dx.doi.org/10.1016/j.firesaf.2005.12.004

[5] Rein, G., Lautenberger, C., Fernandez-Pello, C., Torero, J., and Urban, D., (2006). Application of genetic algorithms and thermogravimetry to determine the kinetics of polyurethane foam in smoldering combustion. Combustion and Flame 146: 95-108.

http://dx.doi.org/10.1016/j.combustflame.2006.04.013

[6] Matala, A., Hostikka, S. and Mangs, J., 2009. Estimation of Pyrolysis Model Parameters for Solid Materials Using Thermogravimetric Data. Fire Safety Science 9: 1213-1223. http://dx.doi.org/10.3801/IAFSS.FSS.9-1213

[7] Lautenberger, C., and Fernandez-Pello, C., (2009) Generalized pyrolysis model for combustible solids. Fire Safety Journal 44: 819-839. http://dx.doi.org/10.1016/j.firesaf.2009.03.011

[8] Chaos, M., Khan, M.M., Krishnamoorthy, N., de Ris, J.L., and Dorofeev, S.B., "Evaluation of optimization schemes and determination of solid fuel properties for CFD fire models using benchscale pyrolysis tests," Proceedings of the Combustion Institute 33 (2), 2011, pp. 2599-2606. http://dx.doi.org/10.1016/j.proci.2010.07.018

[9] Baroudi, D., 1993. "Piecewise least squares fitting technique using finite interval method with Hermite polynomials," VTT Technical Research Centre of Finland, VTT Publications 135, Espoo, Finland. 27 p.

[10] McGrattan, K., Hostikka, S., Floyd, J., Baum, H., Rehm, R., Mell, W., and McDermott, R., "Fire Dynamics Simulator (Version 5) Technical Reference Guide. Volume 1: Mathematical Model," NIST Special Publication 1018-5. Gaithersburg, MD, 2010.

[11] McGrattan, K., McDermott, R., Mell, W., Forney, G., Floyd, J., Hostikka, S., and Matala, A. "Modeling the burning of complicated objects using Lagrangian particles," Proceedings of the Twelfth International Interflam Conference, 2010, pp. 743-753.

[12] Kim, E., Shivkumar, S., and Dembsey, N., "Thermal degradation kinetics modeling for pyrolysis modeling using fire retarded thermoset polymer resins," Proceedings of the Twelfth International Interflam Conference. 2010, pp. 475-486.

[13] Appendix C. DiNenno, P.J. (ed.) SFPE Handbook of Fire Protection Engineering (4 ${ }^{\text {th }}$ ed.), National Fire Protection Association, Quincy, MA 02269, 2008.

[14] Nikolaev, A.V., Gorbatchev, V.M. and Logvinenko, V.A. (1974) Special features of the compensation effect in non-isothermal kinetics of solid-phase reactions, Journal of Thermal Analysis 6: 473-477. http://dx.doi.org/10.1007/BF01914927 